\title{
DEVELOPMENT OF MAN'S USE OF POWER
}

$\mathrm{T}$ HE theme for the Birmingham meeting of the British Association being "Man's Use of Energy", Section H (Archæology and Anthropology) accordingly devoted the afternoon of September 4 to consideration of this topic.

The proceedings were opened by Mr. B. A. L. Cranstone (British Museum) with a paper on "Primitive Man's Use of Power", in which he discussed the factors governing the harnessing of power by modern and ancient peoples possessing stone-age cultures. The Palæolithic stage, in which the dominant material for tools is flaked stone, is normally correlated with a hunting and food-collecting economy; the human group is small and is usually compelled to lead a wandering life. The only portable source of power is the muscle power of the individual, which is applied mainly to missile weapons: the bow, the spear-thrower, the blowgun. Stones may be used for grinding seeds, and the digging stick, which applies the principle of the lever, is found; but requirements in the fields of clothing or containers can be met by the use of skins or other natural objects.

In the Neolithic stage, the use of ground stone or shell tools is correlated with a settled life based on agriculture and stock-breeding. Many new opportunities for using power are presented, but for a variety of reasons relatively few are exploited. Machinery can now be static, and wind- and waterpower are therefore available, together with a new source in the domesticated animal. Many new requirements of containers and buildings are realized, and the relative scarcity of skins for clothing (except among pastoral peoples) leads to the invention of the loom. But water- and wind-power are not harnessed, except in the case of the sailing boat, and milling or water-raising machinery is not developed.

The reason cannot lie in lack of manual skill; the Polynesians, for example, made boats with which they populated the Pacific. Mr. Cranstone suggested that one reason lay in the lack of metal tools, pointing out that primitive machinery must usually be made of wood, and that wooden working parts wear out quickly. The labour of constantly replacing them with stone tools would neutralize the economic value of the machine. Machinery, including the wheel, did not appear in the ancient civilizations of the Near East until copper tools were available; and in ancient Mexico, though the wheel was known, it was only used on toys, suggesting that its application to transport may not have been economically profitable.

Prof. H. F. Humphreys (University of Birmingham) suggested that $\mathrm{Mr}$. Cranstone might have underestimated other factors, such as the innate conservatism of primitive peoples. It was also suggested that a hard wood such as lignum vitæ makes a durable bearing, and that the hard work caused by friction may be as important as the wear on moving parts.

Mr. A. Stowers (Science Museum, London) contributed a paper on "Some Primitive Applications of Power to Pumping and Blowing", which was read by $\mathrm{Mr}$. Adrian Digby and was illustrated with lantern slides. Mr. Stowers pointed out that means of pumping water and blowing air were two of the fundamental requirements of civilization, because the earliest civilizations were based on irrigation agriculture; in some countries (for example, Holland) land could only be reclaimed by pumping and drainage; with the development of mining, draining and artificial ventilation became essential ; and an artificial blast was necessary in the smelting of ores.

The first power resource was man-power. Later, domestic animals became available, and their tractive effort had usually to be converted to rotary motion by means of gearing and rotating shafts. Waterwheels provided greater power ; but, like wind-power, water-power was unreliable compared with animal power.

In the Primitive, Classical and Middle Ages, most of the steps in man's increasing control of energy were probably due to the requirements of pumping machinery ; for this, compared with other machines, required more power which had to be transmitted over increasing distances. Up to the end of the fifteenth century, the maximum power from a rotative prime mover was a fow horse-power transmitted up to-about $200 \mathrm{ft}$. by ropes; but by the end of the seventeenth century single water-wheels of about 20 h.p. and transmission up to a quarter of a mile by reciprocating rods were achieved. Mr. Stowers concluded by explaining that smelting and other processes in copper-and iron-working depended on the use of some form of bellows to increase the heat of the furnace, and showed examples of hand- and footoperated bellows from ancient and modern peoples.

Mr. Digby emphasized that the machine is a specialized device (unlike generalized tools which have a number of uses) and will only be developed in response to a sustained and clear need; the primitive machine develops a low horse-power and requires a large amount of maintenance. $\mathrm{He}$ also suggested that the use made by primitive man of the time saved by a new machine should be investigated. Sir Harold Hartley (president of the British Association), referring to his experience in South Africa, said that the value of water raised by an improved method depends on the skill of the native user, who among peoples not accustomed to irrigation may lack the necessary technical skills, such as a sense of levels.

Lastly, Mr. G. E. Fussell read a paper on "Agricultural Change and the English Village". He showed that, in the Middle Ages, though 90 per cent of the population was engaged in farming, agricultural technique was not sufficiently advanced to provide an assured food supply for all. This position remained practically unchanged until the middle of the eighteenth century, though the structure of society and the ownership of land had changed radically; farming practice had improved, but not enough to compensate for the increase of population. New crops, improved rotations, selective stock breeding, and the gradual introduction of implements such as the seed drill and threshing machine increased production, but by 1850 the population was still outstripping the food supply. The medieval villein could not produce an adequate food supply; the villager of 1850 could not obtain a wage high enough to allow him to buy it.

After 1850, improvements, some introduced long before, caused an accelerated increase in yields. The changes included the introduction of new fertilizers, government loans to assist drainage schemes, the 
adoption of the steam engine as the power unit and many new machines for use in field and barn. But the villager shared relatively little in this improvement. From 1700 until about 1900, when more varied fare became available, the main changes in rural diet were a decrease in the consumption of milk and a heavy increase in that of potatoes.

The two World Wars, with the consequent emphasis on cereal production, the increased rate of technical development and particularly the substitution of tractor-for animal-power have completely changed the farm worker's status. Rural housing still compares unfavourably with that of the towns; but in wages and clothing the farm worker has achieved equality, and his food supply is now superior to that of the urban population.

Mr. Fussell finally suggested that the farmer and farm-worker can only achieve equality with the rest of the community when the emphasis is on cereal and potato production, and the whole population is reduced to a regulated diet.

Dr. R. N. Salaman (president of Section H) said that the modern use of the tractor made deep ploughing possible, and on heavy land this improved drainage and greatly increased yields. The farm labourer is becoming a mechanic; the farmer himself must supply the agricultural knowledge, and is far better equipped in this sense than his ancestors.

\section{B. A. L. Cranstone}

\section{LIGHTING OF MUSEUMS AND GALLERIES}

A

DISCUSSION on museum and gallery lighting took place on September 5 during the Birmingham meeting of the British Association under the chairmanship of the president of Section A (Physics and Mathematics), Prof. E. H. Neville.

Mr. W. E. Rawson-Bottom (Ministry of Works) referred in his paper to the demand for better lighting which has come about generally, and to the enhanced. public interest in museums. Standardized methods have not been found possible : each case should be individually treated. But whatever the system, attention should be directed naturally to the exhibits, and not to a number of bare lamps or fittings which are themselves objects of high brightness. The aim should be to produce an effect without an apparent cause. Lack of interest sometimes arises from an unduly even level of distribution of illumination over a larger area, although on occasions this is desirable.

Fluorescent lamps are now becoming increasingly available in a number of forms. The 'Daylight' type, functioning at a colour temperature of around $4,500^{\circ} \mathrm{K}$., has been found the most effective for general use. 'Warm white' lamps render colour poorly, and moreover they mix badly with natural daylight. Filament lamps still find valuable application in spot-lighting and when brilliance and sparkle are needed.

In order to reduce unpleasant glare, screening of these fluorescent lamps by metal louvres has proved its worth. Showcase lighting is best arranged internally; careful choice of background material and colour will go far to reduce the annoyance of reflexion from the glazing, and keeping it below the nuisance-level.

Experiments have been conducted to do away with the frosted glass top-panels sometimes provided for show-cases, and to replace them by dark-coloured louvres behind which is an efficient reflector. It is assumed, of course, that shelving is of glass, not wood. The observer is, in general, little conscious of the illumination.

If it is intended to use fluorescent lighting in dioramas, the artist responsible will naturally need to work with light of this character, otherwise his distance and perspective will suffer serious distortion.

A number of slides, illustrative of past and present practice in museum lighting, were shown by $\mathbf{M r}$. Rawson-Bottom, from which it was clear what advances have been made in all branches of technique for the æsthetic and truthful illumination of exhibits.

Mr. F. I. G. Rawlins (National Gallery, London), in his paper on the lighting of picture galleries, emphasized the close connexion between gallery architecture and systems of illumination. Dealing with buildings not specifically designed for artificial illumination raises considerable difficulties, which of course became less severe when galleries were treated with modern lighting fully in mind. We have now reached the stage when experiment is likely to yield worth-while results. Between the two World Wars, high-wattage lamps were the rule; they were by no means unsuccessful up to a point, partly because many buildings possess marked vertical lines with which lantern fittings could be made to harmonize reasonably well. The intensity, however, was poor, and the colour-correction inadequate. Spot-lighting at that period was not very successful : it produced a depressing gloom above and around which was generally regarded as forbidding.

The arrival of the fluorescent tube marked a great advance. Its colour properties at once showed improvement, and they are likely to reach still better standards. With good positioning for height and distance, some 25 foot-candles can now be obtained at a height of $5 \mathrm{ft}$. above the floor, compared with about 4 foot-candles fifteen years ago, using 1,500watt gas-filled lamps.

For pictures, backgrounds are of prime importance, especially when looking at relatively small paintings. Backgrounds should be selected from materials having a low coefficient of reflexion, if distraction is to be avoided. Mr. J. Bickerdike has made tests of a preliminary character, which show that pictures possess reflectivities of around $10,20,35$ per cent, of which 20 per cent is far the most common. This, then, gives a hint of how backgrounds should be chosen, and it is remarkable how pleasing they are, when of this order of reflectivity. In conclusion, $\mathrm{Mr}$. Rawlins suggested that some variety of light and shade is to be welcomed, in preference to an overall uniformity of brightness-level throughout a picture gallery. A number of slides demonstrated the effect of intensity distribution and backgrounds at the National Gallery, London.

In opening the general discussion, the chairman asked what steps are being taken to eliminate the irritating reflexions arising from the glazing of pictures. He also inquired whether anything is being done to encourage students to study specifically the subject of museum and gallery lighting. The first question raises many difficulties : a partial solution is to avoid windows opposite, and to provide dark walls on that side; but this does not get rid of the reflexion from the spectator's own person. There are, of course, a number of palliatives; but the basic course is to remove the glass altogether, which is 